\title{
The Implications of Ridehailing for Risky Driving and Road Accident Injuries and Fatalities
}

David S. Kirk [Corresponding Author]

Nuffield College and Department of Sociology, University of Oxford

Correspondence to: Nuffield College, New Road, Oxford OX1 1NF, United Kingdom

+441865278599

david.kirk@sociology.ox.ac.uk

\section{Nicolo Cavalli}

Carlo F. Dondena Centre for Research on Social Dynamics and Public Policy, Bocconi University via Guglielmo Rontgen 1, 20136 Milan, Italy

and

Department of Sociology and Nuffield College, University of Oxford, United Kingdom.

Nuffield College, University of Oxford

New Road, Oxford OX1 1NF, United Kingdom

\section{Noli Brazil}

Department of Human Ecology, University of California, Davis Hart Hall, Davis, California 95616, United States 


\title{
THE IMPLICATIONS OF RIDEHAILING FOR RISKY DRIVING AND ROAD ACCIDENT INJURIES AND FATALITIES
}

\begin{abstract}
The nature of transportation has fundamentally transformed in recent years with the rise of ridehailing providers such as Uber. Yet, few studies have examined whether there is an association between ridehailing and rates of road accident injuries, and virtually all of the existing studies focus on the exceptional case of the United States. In this study, we exploit differences in the timing of the deployment of Uber across Britain to test the association between the advent of Uber's ridehailing services and rates of fatal and non-fatal road accidents. We find that the deployment of Uber in Great Britain is associated with a marginally significant reduction in the number of serious road accident injuries (e.g., fractures and internal injuries), although not the number of serious accidents. Slight injuries (e.g., sprains and bruises) declined outside of London after the rollout of Uber, but increased within London. We do not observe a statistically significant association between Uber and traffic fatalities. One interpretation for the decline in serious road injuries is that Uber may be a substitute form of transportation for risky drivers, including drink-drivers. However, ridehailing is also a substitute for public transit, particularly buses. The increase in the number of cars on the road may explain why slight injuries increased in London following Uber's rollout.
\end{abstract}

Keywords: road accidents; injuries; traffic fatalities; drink driving; Uber; rideshare; ridehailing; Great Britain 


\section{INTRODUCTION}

In Great Britain, road accident fatalities and injuries have steadily declined since the mid-1960s, due in part to efforts to improve road and vehicle safety and to reduce the extent of drink-driving. ${ }^{1}$ Yet it appears that progress on reducing road fatalities as well as serious injuries has stalled and even begun to reverse course, with serious injuries increasing nearly 12\% from 2014 to $2018 .{ }^{2,3}$ Along with suicide and drug overdose, traffic fatalities are among the leading causes of death of 15 to 29 year olds in the UK as well as worldwide. ${ }^{1,4}$

The stalled progress on reducing traffic fatalities might be suggestive of the fact that existing interventions have diminishing returns and may not result in much further progress on reducing already low levels of fatalities. Yet, the nature of transportation has fundamentally transformed in recent years with the advent of Uber and its ridehailing competitors. Since its service launched in San Francisco in 2010, Uber has experienced phenomenal growth, reaching 6 continents, more than 70 countries, and 700 cities through $2018 .{ }^{5}$ Whilst it took Uber roughly six years before it reached the 1 billion ride milestone (March 2016), it took just 2.5 more years (September 2018) to reach 10 billion total rides. ${ }^{6}$

Given the convenience and low cost, Uber may be a potential countermeasure for reducing the roughly 1,800 road accident fatalities, and 25,000 serious injuries that occur each year in Great Britain, including the roughly 230 deaths and 1,250 serious injuries from drink-driving. ${ }^{2,7}$ Expanding the availability and lowering the cost of alternate transportation options should, in theory, reduce the number of drink-driving occurrences and fatalities. Conversely, Uber may actually increase road accidents by increasing the number of vehicles and vehicle miles travelled on Great Britain's roads. ${ }^{8}$ Indeed, Uber and its competitor Lyft account for roughly two to three percent of all vehicle miles 
travelled in many major Western cities, and in some locations it is dramatically higher (e.g., San Francisco, 13\%; Boston, $8 \%$; Washington, DC, 7\%). ${ }^{9}$ Moreover, drowsy driving is one of the leading causes of motor vehicle accidents, which is a problem that may be particularly acute among Uber and other ridehailing drivers since many work multiple jobs for long hours. ${ }^{10,11}$

Despite the fact that two of Uber's top five markets are located outside of the United States, and that the majority of ridehailing trips worldwide occur beyond US borders, most studies of the relationship between the advent of Uber and road accidents have focused on the United States (the exceptions being studies of Chile and South Africa). ${ }^{6,12-14}$ Research from the United States has produced mixed findings, with some research observing a decline in at least some types of traffic fatalities following the rollout of Uber, but with other studies finding evidence for either no effect of Uber or even an increase in fatalities. ${ }^{8,15-20}$ Still, the United States is exceptional with respect to traffic fatalities. OECD data reveals that the rate of traffic deaths per million US inhabitants in 2017 (114.1) far exceeded the vast majority of Western countries, with the only exception being Argentina (122.4). ${ }^{21}$ The rate in the United Kingdom was 28.1 per million inhabitants. Hence, even if there is a reduction in traffic fatalities following the advent of Uber in US cities, there may not be a similar relationship in other countries that generally have far less risk of traffic fatalities. In fact, for those countries with far lower rates of road accidents than the US, any added traffic congestion from ridehailing may increase accident risk rather than lower it.

In sum, despite the massive expansion of Uber's presence over the last few years to more than 70 countries worldwide and more than 10 billion rides, there have been relatively few studies of the implications of Uber for traffic fatalities and, especially, non-fatal injuries, and nearly all of that research is focused on the exceptional case of the United States during the initial years of adoption. 
In this study, we turn the lens to Great Britain, and ask whether the deployment of Uber's ridehailing services has been associated with a significant change in the number of road accident injuries and fatalities. Ridehailing is a private sector intervention that may have transformative potential to change the nature of road safety worldwide, and it therefore deserves empirical inquiry. If ridehailing yields declines in drink driving and traffic fatalities in Great Britain and beyond, it may be advantageous for cities to partner with ridehailing companies to promote its use. Conversely, if ridehailing actually increases the risk of road accidents and fatalities, it may be advisable for cities to be cautious in their licensing and regulations with respect to ridehailing.

\section{MATERIALS AND METHODS}

The geographic units of analysis in our study are local government authorities in Great Britain. There were 326 local authorities in England, 32 in Scotland, and 22 in Wales as of 2016 (380 total), as recorded in data files of the Office of National Statistics. To arrive at our sample of 378 local authorities, we merged the Isles of Scilly local authority to the Cornwall authority. The Isles of Scilly are small islands located off the coast of Cornwall with a total population of just over 2,000. Additionally, we exclude from our analysis the City of London Corporation (as opposed to the Greater London metropolitan area). The City of London is the small, historic centre of London with a small residential population $(\sim 7,000)$ and land area $\left(2.9 \mathrm{~km}^{2}\right)$.

Dependent variables. The dependent variable for our analysis is the monthly number of people injured in road accidents between 2009 and 2017 ( $T=108$; 9 years x 12 months), for 378 local authorities in Great Britain ( $N \times T=40,824$; note: a parallel analysis with daily data can be found in Supplementary Appendix C). We downloaded public data from the Department for Transport containing detailed information about single instances of accidents involving personal injuries that 
occurred on the public roads of Great Britain (England, Scotland, and Wales). Accidents are classified in the data according to the degree of injury severity: "Slight" (such as sprains, whiplash, bruises, and slight shock requiring roadside attention), "Serious" (such as fractures, internal injuries, severe cuts, concussions, burns, and loss of limbs), and "Fatal." The Department for Transport provides data on drink-driving accidents by region in Great Britain, but not by local authority. Hence, we are unable to directly analyse the relationship between the rollout of Uber and drink-driving related injuries.

Predictor. The main independent variable employed in our analysis is a time-varying dummy variable indicating the availability of Uber services in a local authority. The dummy is set equal to one starting from the month in which Uber was introduced. We obtained information on the timing of the rollout of Uber from the Newsroom section of the Uber Technologies, Inc. website dedicated to the United Kingdom (see Supplementary Table A.1 for details of exact timings of rollouts), cross-validated with information from general news outlets.

Control Variables. We control for a variety of time- and geographically-varying factors associated with road accident injuries. These include quarterly unemployment rates, lagged by one quarter, derived from local labour market statistics disseminated by the Office of National Statistics, included to account for differences in area-level economic activity that have been found to correlate with road accident mortality. As the risk of accidents vary with the number of people on the road, we also include monthly fuel price as a control, given its influence on automobile use (see Supplementary Appendix A for further details about all controls). We additionally control for the total population size (per 100,000 residents) in each local authority in a given year. 
Furthermore, the introduction of Uber has direct effects on the supply of rides, both by displacing existing taxi services via increased competition, and by generating a new "ride-hailing" market, thus inviting the entry of ridehailing competitors. In order to model variations in the supply of rides thus generated, we add a control variable that combines data from the Department for Transport on the number of taxi and other private hire vehicles (PHV) per hundred residents in a given year.

Finally, we account for the fact that, in the timeframe under analysis, two new injury reporting systems, COPA (Case Overview and Preparation Application, adopted in London) and CRASH (Collision Recording and Sharing), were introduced in about half of British police forces. The introduction of these reporting systems is associated with some variation in counts of Slight and Serious injuries. ${ }^{22,23}$ Therefore, in our models we set a dummy variable equal to one for months in which COPA or CRASH were in use by local police forces (see Supplementary Appendix A for further detail about the rollout of CRASH and COPA). Table 1 presents the summary statistics for all variables used in our analysis. Detailed information about all data sources used to construct these variables is found in Supplementary Appendix A.

[Table 1 here]

Statistical Methods. To identify the effect of the introduction of Uber services on the number of road accident injuries, we exploit differentials in the timing of Uber's rollout across British local authorities between 2009 and 2017. We compare changes in injuries for those local authorities where Uber was introduced to the contemporaneous changes in injuries for the local authorities where Uber was not yet present. For estimation, we use negative binomial regression models, which are appropriate in instances of over-dispersed data such as ours. We adjust for exposure to the risk of road accident injury across local authorities and months with the inclusion of an exposure variable, 
measured as the number of vehicle-miles travelled (VMT) in a given local authority-month. We cluster standard errors at the licensing authority area $(N=347)$, and in Supplementary Appendix B we present sensitivity analyses with alternative choices for clustering our standard errors (i.e., by local authority, police force area, and region).

We include local authority, month, and year fixed effects in our models, entered as vectors of dummy variables. Including local authority fixed effects allows us to control for area-level time-invariant factors correlated with the risk of injuries. The month fixed effects control for factors that vary month to month but are local authority and year invariant, such as travel patterns. The year fixed effects account for factors that affected all local authorities in all months in a given year, such as changes in national regulations. All analyses are conducted in Stata version 16.

\section{RESULTS}

Main analysis. In Table 2, we present results for four different dependent variables measuring the monthly count of road accident injuries (Total, Slight, Serious, and Fatal injuries). We fail to reject the null hypothesis of no association between the availability of Uber and the number of Total, Slight, and Fatal injuries. However, for Serious injuries, we find evidence of a marginally significant negative relationship with the introduction of Uber's service. Uber is associated with a 9\% reduction in Serious injuries (CI -0.178 to 0.004; $\mathrm{p}=0.062)$.

[Table 2 here]

Robustness checks. In Tables 3 and 4, we present four different sensitivity checks in order to better characterise and test the robustness of the results presented in the previous section. First, we check whether our inferences are sensitive to outlier accidents by replacing our dependent variable with one 
where the maximum number of injuries per accident is set to ten for those accidents with ten or more injuries (Table 3, model 1). Second, we estimate our model only for accidents that occurred between $5 \mathrm{pm}$ on Friday and $5 \mathrm{am}$ on Sunday, to test whether we find a different association between Uber availability and road injuries on weekends (Table 3, model 2). Third, we consider whether results from our models are sensitive to restricting the sample to large areas with more than 100,000 residents (Table 3, model 3). Fourth, we test for a lagged effect of Uber by replacing the binary Uber indicator with a variable categorizing observations into (1) no Uber service present, (2) Uber deployed for one month or less, and (3) Uber deployed for more than one month (Table 4). In Supplementary Table B.3, we also present models using a cut-off of three months and also six months instead of one month. Across these robustness checks, we observe findings highly consistent with the results presented in Table 2.

[Table 3 here]

[Table 4 here]

Heterogeneity of treatment effects. In our final set of analyses, we investigate potential heterogeneity in treatment effects for the London metropolitan area versus the rest of Great Britain, with the inclusion of an interaction between the indicator of Uber availability in a given month and a dummy variable set to one to indicate an observation is from London. To ease interpretation, we present incidence rate ratios (IRRs) in Table 5.

Focusing first on the top row of results in the table, an IRR for the Uber availability variable is interpreted as the expected rate of road accident injuries in local authorities outside of London with Uber relative to local authorities outside of London without Uber. An IRR less than one indicates a reduction in road accident injuries after Uber's deployment, while an IRR greater than one suggests 
an increase. In stark contrast to our overall findings from Table 2, we find that the deployment of Uber is associated with a decline in Total and Slight road accident injuries outside of London; Uber is associated with an estimated 7\% reduction in both Total and Slight injuries across the rest of Great Britain. However, outside of London, we do not observe an association between Uber and Serious or Fatal injuries.

[Table 5 here]

Interpreting interactions in nonlinear models is challenging, but a focus on the IRRs allows us to interpret interactions on a multiplicative scale rather than on an additive scale. ${ }^{24}$ In the case of an interaction, the IRR technically represents the ratio of two IRRs: the effect of Uber on road accident injuries within London over the effect of Uber on injuries outside of London. Accordingly, the IRRs for our interaction term reveal that, for Total and Slight injuries, the effect of Uber is significantly stronger in London than outside. For Serious and Fatal injuries, we find the opposite. For Slight injuries, Uber is associated with an 18\% increase in injuries in London boroughs $(1.27 \times 0.93=1.18)$. In contrast, for Serious injuries Uber is associated with a 19\% decrease in injuries in London $(0.81 *$ $1.00=0.81)$

To further assess the robustness of our findings, in Supplementary appendices B, C, and D we examine whether our results are robust to: (1) clustering standard errors at the local authority, police force area, or region rather than the licensing-area (Supplementary Table B.1), (2) using alternative specifications of the exposure variable (Supplementary Table B.2) and the Uber availability variable (Supplementary Table B.3), (3) using daily counts of road accident injuries instead of monthly counts (Supplementary Tables C.1 - C.4), and (4) using the number of accidents rather than the number of injuries as our dependent variable (Supplementary Tables D.1 - D.5). Across all these specifications, we largely find 
results consistent with our core inferences from Table 2. The main difference occurs when using the number of accidents rather than the number of injuries as our dependent variable. In this case, we no longer observe a marginally significant association between Uber's rollout and Serious accidents (Supplementary Table D.2 and Table D.4).

\section{DISCUSSION}

Findings presented in this study reveal that the deployment of Uber in local authorities in Great Britain has generally been associated with a marginally significant decline in Serious road accident injuries (e.g., fractures and internal injuries). In aggregate across all local authorities, we do not observe a statistically significant association between Uber and Slight or Fatal injuries, although there is some evidence for heterogeneity in the finding related to slight injuries between London and non-London areas.

Caveats and limitations of our research design are important to note. First, we lack individual-level information about Uber rides and users. Therefore, it is not possible to examine at the person-level to what extent risk-prone drivers make use of Uber's services or the driving histories of Uber drivers. On the latter point, Uber's internal analysis for their 2017-18 US Safety Report indicates that the rate of motor vehicle fatalities involving an Uber driver, per vehicle mile travelled, is half of the rate in the total population. ${ }^{25}$ However, comparable analysis has not yet been published about the UK, and Transport for London's recent decision not to renew Uber's licence in London suggests that Uber drivers present an unacceptable public safety risk in one of the company's top markets. ${ }^{26}$ Second, we were unable to examine Uber's association with drink-driving accidents as some previous studies have done. Despite these caveats and limitations, this study extends previous research by examining countries (Great Britain) so far neglected in this literature, which is critical to 
do since most of the extant literature focuses on the exceptional case of the United States, and does not examine distinctions by levels of injury severity.

There are several explanations for why the availability of Uber appears to be associated with a marginally significant reduction in Serious road accident injuries. For instance, Uber may be an alternative form of transportation used by the types of risky drivers, including drink-drivers, that are at greater risk of getting in very serious accidents.

However, there are several explanations for why the beneficial effects of ridehailing may be limited to Serious accidents. With respect to fatalities, because so much progress has been made in Great Britain since the 1960s in producing safer cars and roadways, even a significant innovation such as Uber may have little impact on reducing the already low levels of fatalities. Additionally, Uber may be a substitute for taxis and other forms of public transportation but not a substitute for moderately risky driving (i.e., the type of drivers who get into accidents involving "Slight" injuries). Indeed, research reveals that the advent of Uber in the United States is associated with a decline in the use of bus services..$^{27,28}$ Accordingly, if former public transit users are the predominant Uber customer rather than moderately risky drivers, the number of moderately risky drivers on the road would not decline. If ridehailing through Uber is a substitute for public transit, then the number of cars and even the number of risky drivers (e.g., such as those who are sleep deprived) on the road may even increase, which may then lead to increases in Slight injuries, especially in a dense city like London where Uber use is greater.

\section{DATA SHARING}

All data and Stata code will be made available on Github. 


\section{REFERENCES}

1. Jackson L., Cracknell R. Road accident casualties in Britain and the world. London, UK: House of Commons Library; 2018. Available from:

https://researchbriefings.parliament.uk/ResearchBriefing/Summary/CBP-7615.

2. Department for Transport. Reported road casualties in Great Britain: main results 2018.

London, UK: Department for Transport; 2019. Available from:

https://assets.publishing.service.gov.uk/government/uploads/system/uploads/attachment dat a/file/820562/Reported road casualties - Main Results 2018.pdf.

3. Department for Transport. Reported road casualties in Great Britain: main results 2014.

London, UK: Department for Transport; 2015. Available from:

https://assets.publishing.service.gov.uk/government/uploads/system/uploads/attachment dat a/file/438040/reported-road-casualties-in-great-britain-main-results-2014-release.pdf.

4. Office of National Statistics. Death registration summary tables - England and Wales. Newport, UK: Office of National Statistics; 2018. Available from:

https://www.ons.gov.uk/peoplepopulationandcommunity/birthsdeathsandmarriages/deaths/d atasets/deathregistrationssummarytablesenglandandwalesreferencetables.

5. Uber.com [Internet]. San Francisco, CA [cited 2019 July 27]. Available from: https://www.uber.com/global/en/cities/.

6. Uber Technologies, Inc. Form S-1 Registration Statement. EDGAR. Securities and Exchange Commission, 2019. Available from:

https://www.sec.gov/Archives/edgar/data/1543151/000119312519103850/d647752ds1.htm

7. Department for Transport. Reported road casualties in Great Britain: 2017 annual report. London, UK: Department for Transport; 2018. Available from: 
https://assets.publishing.service.gov.uk/government/uploads/system/uploads/attachment dat a/file/755698/rrcgb-2017.pdf.

8. Barrios J. M., Hochberg Y. V., Yi H. The cost of convenience: ridesharing and traffic fatalities. SSRN [Preprint] 2019. Available from: http://dx.doi.org/10.2139/ssrn.3259965.

9. Pangilinan C. Learning more about how our roads are used today. Medium.com [online], 5 August 2019. Available from: https://medium.com/uber-under-the-hood/learning-moreabout-how-our-roads-are-used-today-bde9e352e92c.

10. Tefft B. C. Prevalence of motor vehicle crashes involving drowsy drivers, United States, 2009 2013. Washington, DC: AAA Foundation for Traffic Safety; 2014.

11. Berneking M., Rosen I. M., Kirsch, D. B., Chervin R. D., Carden K. A., Ramar K., et al. The risk of fatigue and sleepiness in the ridesharing industry: an American Academy of Sleep Medicine position statement. J Clin Sleep Med 2018; 14: 683-685.

12. Lagos V., Munoz Á., Zuleher C. Gender-specific benefits from ride-hailing apps: evidence from Uber's entry in Chile. SSRN [Preprint] 2019. Available from: http://dx.doi.org/10.2139/ssrn.3370411.

13. Huang Y. H., Majid F., Daku M. Estimating effects of Uber ride-sharing service on road trafficrelated deaths in South Africa: a quasi-experimental study. J Epidemiol Community Health 2019; 73: 263-271.

14. ABI Research. 16 Billion Ride-Hailing Trips Completed Globally in 2017 - 24 Billion Trips expected in 2018. Oyster Bay, NY: ABI Research; 2018. Available from: https://www.abiresearch.com/press/16-billion-ride-hailing-trips-completed-globally-2017-24billion-trips-expected-2018/

15. Greenwood B. N., Wattal S. Show me the way to go home: an empirical investigation of ridesharing and alcohol related motor vehicle fatalities. MIS Quarterly 2017; 41: 163-187. 
16. Martin-Buck VII, F. P. Responsible options: empirical analyses on the effects of alternative transportation on drunk driving. Austin, TX: University of Texas at Austin; 2017. Available from: https://repositories.lib.utexas.edu/handle/2152/60411.

17. Peck J. L. New York City drunk driving after Uber. City University of New York Graduate Center [Preprint] 2017. Available from: https://academicworks.cuny.edu/cgi/viewcontent.cgi?referer=https://scholar.google.co.uk/\& httpsredir $=1 \&$ article $=1012 \&$ context $=$ gc econ wp.

18. Dills A. K., Mulholland S. E. Ride-sharing, fatal crashes, and crime. Southern Economic Journal 2018; 84: 965-991.

19. Morrison C. N., Jacoby S. F., Dong B., Delgado M. K., Wiebe D. J. Ridesharing and motor vehicle crashes in 4 US cities: an interrupted time-series analysis. Am J Epidemiol 2018; 187: 224232.

20. Brazil N., Kirk D. S. Uber and metropolitan traffic fatalities in the United States. Am J Epidemiol 2016; 184: 192-198.

21. Organisation for Economic Co-operation and Development (OECD). Road accidents. [Internet]. 2019 [cited 2019 July 27]. Available from: https://data.oecd.org/transport/roadaccidents.htm.

22. Department for Transport. Reported road casualties Great Britain, annual report: 2016. London, UK: Department for Transport; 2017. Available from: https://www.gov.uk/government/statistics/reported-road-casualties-great-britain-annualreport-2016.

23. Office for National Statistics. Estimating and adjusting for changes in the method of severity reporting for road accidents and casualty data: interim report. Newport, UK: Office of National Statistics; 2018. 
24. Buis M. L. Stata tip 87: interpretation of interactions in nonlinear models. Stata J 2010; 10: 305308.

25. Uber Technologies, Inc. 2017-2018 US Safety Report. San Francisco, CA: Uber; 2019. Available from: https://www.uber-

assets.com/image/upload/v1575580686/Documents/Safety/UberUSSafetyReport $201718 \mathrm{Fu}$ llReport.pdf.

26. Burridge T. Uber loses licence to operate in London. BBC News [online], 25 November 2019. Available from: https://www.bbc.co.uk/news/business-50544283.

27. Babar Y., Burtsch G. Examining the impact of ridehailing services on public transit use. SSRN [Preprint] 2017. Available from: http://dx.doi.org/10.2139/ssrn.3042805.

28. Pan Y., Qiu L. Is Uber helping or hurting mass transit? an empirical investigation. SSRN [Preprint] 2018. Available from: http://dx.doi.org/10.2139/ssrn.3267059. 
Table 1 . Summary statistics

\begin{tabular}{|c|c|c|c|c|c|}
\hline & & Mean & SD & Min & Max \\
\hline \multicolumn{6}{|c|}{ Dependent Variables } \\
\hline \multirow[t]{4}{*}{ Injuries: } & Total & 42.7 & 33.6 & 0 & 460 \\
\hline & Slight & 35.5 & 29.3 & 0 & 404 \\
\hline & Serious & 6.5 & 6.0 & 0 & 115 \\
\hline & Fatal & 0.7 & 1.6 & 0 & 55 \\
\hline \multicolumn{6}{|c|}{ Predictor } \\
\hline \multicolumn{2}{|c|}{ Uber Available } & 0.1 & 0.3 & 0 & 1 \\
\hline \multicolumn{6}{|c|}{ Controls } \\
\hline \multicolumn{2}{|c|}{ Lagged Unemployment Rate (\%) } & 6.1 & 2.4 & 1.8 & 16.6 \\
\hline \multicolumn{2}{|c|}{ Total Population (per 100,000) } & 1.6 & 1.1 & 0.2 & 11.4 \\
\hline \multicolumn{2}{|c|}{ Taxi \& PHVs (\%) } & 3.0 & 9.3 & 0.0 & 69.8 \\
\hline \multicolumn{2}{|c|}{ Fuel Price (GBP per lt.) } & 1.2 & 0.1 & 0.9 & 1.5 \\
\hline \multicolumn{2}{|c|}{ CRASH/COPA Rollout } & 0.1 & 0.3 & 0.0 & 1.0 \\
\hline \multicolumn{6}{|c|}{ Exposure } \\
\hline \multicolumn{2}{|c|}{ Monthly VMT } & 291.2 & 238.3 & 5.9 & 867.5 \\
\hline \multicolumn{2}{|c|}{ Yearly VMT } & 3495.8 & 2849.5 & 80.0 & 9.9 \\
\hline \multicolumn{2}{|c|}{ Vehides Registered (\%o pop) } & 592.1 & 146.0 & 174.7 & 1604.8 \\
\hline
\end{tabular}


Table 2. Association between Uber rollout and the number of road accident injuries

\begin{tabular}{|c|c|c|c|c|}
\hline & Total & Slight & Serious & Fatal \\
\hline \multirow[t]{2}{*}{ Intercept } & $-1.68 * * *$ & $-2.20 * * *$ & $-2.21 * * *$ & $-2.95 * * *$ \\
\hline & $(0.36)$ & $(0.41)$ & $(0.24)$ & $(0.55)$ \\
\hline \multirow[t]{2}{*}{ Uber Available } & 0.01 & 0.03 & $-0.09+$ & 0.02 \\
\hline & $(0.03)$ & $(0.04)$ & $(0.05)$ & $(0.06)$ \\
\hline \multirow[t]{2}{*}{ Lagged Unemployment Rate } & 0.00 & 0.00 & $-0.01 *$ & -0.01 \\
\hline & $(0.00)$ & $(0.00)$ & $(0.01)$ & $(0.02)$ \\
\hline \multirow[t]{2}{*}{ Total Population (per 100K) } & $0.49 * *$ & $0.56 * *$ & 0.14 & -0.10 \\
\hline & $(0.15)$ & $(0.17)$ & $(0.10)$ & $(0.20)$ \\
\hline \multirow[t]{2}{*}{ Taxi \& PHVs (\%) } & $0.02 * * *$ & $0.03 * * *$ & $0.01 * * *$ & $0.01 * *$ \\
\hline & $(0.00)$ & $(0.00)$ & $(0.00)$ & $(0.00)$ \\
\hline \multirow[t]{2}{*}{ Fuel Price } & -0.03 & 0.01 & -0.12 & $-1.17 * * *$ \\
\hline & $(0.04)$ & $(0.04)$ & $(0.09)$ & $(0.35)$ \\
\hline \multirow[t]{2}{*}{ CRASH/COPA Rollout } & $0.07 * * *$ & $0.03 *$ & $0.31 * * *$ & 0.07 \\
\hline & $(0.01)$ & $(0.01)$ & $(0.03)$ & $(0.05)$ \\
\hline Local Authority FE & YES & YES & YES & YES \\
\hline Monthly FE & YES & YES & YES & YES \\
\hline Year FE & YES & YES & YES & YES \\
\hline$N$ & 40,824 & 40,824 & 40,824 & 40,824 \\
\hline
\end{tabular}




\section{Table 3. Robustness checks}

\begin{tabular}{cccc}
\hline & $\begin{array}{c}\text { Capped } \\
\text { Injuries } \\
(1)\end{array}$ & Weekends & $\begin{array}{c}\text { Above 100k } \\
\text { Residents } \\
(3)\end{array}$ \\
\hline Number of Injuries: & & $(2)$ & \\
Total & 0.01 & & 0.02 \\
Slight & $(0.03)$ & 0.04 & $(0.04)$ \\
& 0.03 & $(0.03)$ & 0.03 \\
Serious & $(0.04)$ & 0.06 & $(0.05)$ \\
& $-0.09+$ & $(0.04)$ & $-0.08+$ \\
Fatal & $(0.05)$ & -0.06 & $(0.04)$ \\
& 0.02 & $(0.05)$ & 0.03 \\
\hline $\mathrm{N}$ & $(0.06)$ & 0.05 & $(0.06)$ \\
\hline $\mathrm{p}<0.1, * \mathrm{p}<0.05, * * \mathrm{p}<0.01, * * * \mathrm{p}<0.001$. & $(0.09)$ & 28,296 \\
\hline
\end{tabular}

Estimates from negative binomial models. Standard errors in parentheses. The twelve coefficients and standard errors represent results from twelve different regression models: four dependent variables (Total, Slight, Serious, and Fatal injuries) by three robustness tests. All models include controls for the lagged unemployment rate, total population, the rate of taxis and PHVs, fuel price, and CRASH/COPA rollout. All models include local authority, month, and year fixed effects. 
Table 4. Association between Uber rollout and the number of road accident injuries, by the time since Uber's deployment

\begin{tabular}{|c|c|c|c|c|}
\hline & Total & Slight & Serious & Fatal \\
\hline Uber active $\leq$ & -0.01 & 0.00 & 0.01 & -0.30 \\
\hline 1 month & $(0.02)$ & $(0.02)$ & $(0.04)$ & (0.19) \\
\hline Uber active > & 0.01 & 0.03 & $-0.09+$ & 0.04 \\
\hline 1 month & $(0.04)$ & $(0.05)$ & $(0.05)$ & $(0.06)$ \\
\hline$N$ & 40,824 & 40,824 & 40,824 & 40,824 \\
\hline
\end{tabular}

${ }^{+} \mathrm{p}<0.1,{ }^{*} \mathrm{p}<0.05,{ }^{* *} \mathrm{p}<0.01,{ }^{* * *} \mathrm{p}<0.001$.

Estimates from negative binomial models. Standard errors in parentheses. All models include controls for the lagged unemployment rate, total population, the rate of taxis and PHVs, fuel price, and CRASH/COPA rollout. All models include local authority, month, and year fixed effects. The reference group in these models is a category indicating that Uber is not active in a given local authority at a given time point. 
Table 5. Heterogeneity of treatment for London vs. rest of Great Britain

\begin{tabular}{|c|c|c|c|c|}
\hline & Total & Slight & Serious & Fatal \\
\hline \multirow{3}{*}{$\begin{array}{r}\text { Uber } \\
\text { Availability }\end{array}$} & $-0.07 * *$ & $-0.07 * *$ & 0.00 & 0.07 \\
\hline & $(0.02)$ & $(0.03)$ & $(0.03)$ & $(0.07)$ \\
\hline & [0.94] & [0.93] & {$[1.00]$} & [1.07] \\
\hline \multirow[t]{3}{*}{ London } & 1.33 *** & $1.44 * * *$ & $0.67 * * *$ & 0.08 \\
\hline & $(0.04)$ & $(0.04)$ & $(0.06)$ & $(0.12)$ \\
\hline & [3.77] & [4.23] & [1.94] & [1.08] \\
\hline \multirow[t]{3}{*}{ Uber*London } & $0.19 * * *$ & $0.24 * * *$ & $-0.21 * * *$ & $-0.13+$ \\
\hline & $(0.02)$ & $(0.03)$ & $(0.03)$ & $(0.07)$ \\
\hline & {$[1.20]$} & {$[1.27]$} & {$[0.81]$} & {$[0.88]$} \\
\hline$N$ & 40,824 & 40,824 & 40,824 & 40,824 \\
\hline \multicolumn{5}{|c|}{${ }^{+} \mathrm{p}<0.1, * \mathrm{p}<0.05, * * \mathrm{p}<0.01, * * * \mathrm{p}<0.001$} \\
\hline \multicolumn{5}{|c|}{$\begin{array}{l}\text { Estimates from negative binomial models. Standard errors in parentheses, and } \\
\text { incidence rate ratios in brackets below the standard errors. All models include controls } \\
\text { for the lagged unemployment rate, total population, the rate of taxis and PHVs, fuel } \\
\text { price, and CRASH/COPA rollout. All models include local authority, month, and year } \\
\text { fixed effects. }\end{array}$} \\
\hline
\end{tabular}


THE IMPLICATIONS OF RIDEHAILING FOR RISKY DRIVING AND ROAD ACCIDENT INJURIES AND FATALITIES

SUPPLEMENTARY INFORMATION 


\section{Supplementary Appendix A. Further details of research design}

Sample: Our analyses use Great Britain's local authorities as our geographic unit of analysis. As of 2016, there were 326 total local authorities in England, 32 in Scotland, and 22 in Wales (380 total). ${ }^{1}$

In England, the structure of local government varies in different parts of the country, and there are five broad types of local authorities: county councils, district councils, unitary authorities, metropolitan districts, and London boroughs. Reorganization and consolidation of authorities occurs from time-to-time, so the number of local authorities and their boundaries are not completely static. In some parts of England, local government functions as a two-tier system with a local district council and then a county council covering the wider county area (containing multiple district councils). In this two-tier system, both the district and county councils provide services to the population. In contrast, other parts of England have a single (i.e., unitary) tier structure of local government, with a single authority providing all government services.

Of the 326 local authorities in England, there are 201 district councils, 56 unitary councils (which includes the Isles of Scilly), 36 metropolitan districts, 32 London boroughs, and the City of London. ${ }^{2,3}$ Additionally, there are 27 county councils not included in the total of 326 . These county councils are omitted from our dataset because they cover the same areas as the district councils. Including them would effectively lead to double-counting of those areas with two-tiered local government.

As noted in the main text, to arrive at a sample of 378 local authorities, we merged one local authority (Isles of Scilly) and dropped one from our analysis (City of London). The Isles of Scilly are small islands located off the coast of Cornwall with a total population of just over 2,000. Many of 
the government services offered to Isles of Scilly residents are provided by the Cornwall Council. Moreover, many government data collections already merge the Isles of Scilly to Cornwall. We chose to similarly merge the Isles of Scilly local authority to the Cornwall authority.

We exclude from our analysis the City of London Corporation (as opposed to Greater London). The City of London is the small, historic centre of London with a small residential population $(\sim 7,000)$ and land area $\left(2.9 \mathrm{~km}^{2}\right)$. It also is an extreme outlier in terms of the number of taxis and private hire vehicles (PHV) over the total population: between 2009 and 2017, 281.9 taxis and 743.6 PHVs were registered per hundred residents on a yearly average in the City of London, versus a Great Britain average of 1.6 and 4.1 respectively.

Throughout the article, we treat the 32 Greater London local authorities as separate entities rather than as a single geographic unit. Although Uber was introduced in these authorities at the same time, we choose this strategy to better take into account intra-London variations, which for several of the variables used in our analyses are comparable or even greater within London than across areas outside of London. We also run a set of sensitivity tests dropping London from the estimation sample, and report results with and without the inclusion of London.

Dependent variables. The dependent variable for our analysis is the monthly number of people injured in road accidents between 2009 and 2017 ( $T=108$; 9 years x 12 months), for 378 local authorities in Great Britain $(N \times T=40,824) .{ }^{4}$ We gather public data from the Department for Transport containing detailed information about single instances of accidents involving personal injuries that occurred on the public roads of Great Britain (England, Scotland, and Wales). Accidents are classified in the data according to the degree of injury severity: "Slight" (such as sprains, whiplash, 
bruises, and slight shock requiring roadside attention), "Serious" (such as fractures, internal injuries, severe cuts, concussion, burns, and loss of limbs), and "Fatal" (cases of death within 30 days of the accident). ${ }^{5,6}$

Predictor. The main independent variable employed in our analysis is a time-varying dummy variable indicating the availability of Uber services in a local authority. The dummy is set equal to one starting from the month in which Uber was introduced. In additional analyses (Table 4 and Supplementary Table C.3), we replace the binary Uber indicator with a variable categorizing observations into (1) no Uber service present, (2) Uber service active for a short duration (one, three, or six months, depending upon the model), and (3) Uber deployed for a longer duration (more than one, three, or six months, depending upon the model). We obtained information on the timing of the rollout of Uber from the Newsroom section of the Uber Technologies, Inc. website dedicated to the United Kingdom, crossvalidated with information from general news outlets. ${ }^{7}$ See Supplementary Table A.1 for details of exact timings of rollouts.

\section{[Supplementary Table A.1 here]}

Exposure variable: In our analyses, we adjust for exposure to the risk of road accident injury with the inclusion of an exposure variable, measured as the number of vehicle-miles travelled (VMT) in a given local authority-month. This measure was obtained by combining yearly VMT at the local authority level with monthly VMT for the whole of Great Britain, under the assumption that the distribution of VMT across local authorities is broadly constant within each reference year., ${ }^{8,9}$ Accordingly, the coefficient for our treatment variable, Uber availability, represents the effect of the availability of Uber on the rate of occurrence of road injuries over the exposure variable. In Supplementary Appendix B, we assess the robustness of our main results to alternate specifications 
of exposure, and re-estimate our models using three different measures of exposure: local yearly VMT, the total number of vehicles registered in each year by local authority, and yearly population counts for each local authority.

Control variables: Our models include several time-varying control variables in order to account for potential confounding influences. These include the number of taxi and other private hire vehicles (PHVs) per hundred residents ${ }^{10}$ and the total population in the local authority (per 100,000 residents). The measurement of our final three control variables, lagged unemployment, fuel price, and the implementation of the CRASH and COPA injury reporting systems, warrants further description.

Unemployment: The Office of National Statistics, based on data from the Labour Force Survey, publishes information on unemployment statistics by local authority every quarter, with the data covering a rolling 12 -month period. ${ }^{11}$ For instance, one set of unemployment estimates address the period from October 2016 to September 2017 and the next set covers the period from January 2017 to December 2017. We use the midpoint of each 12-month period as our time-varying control of quarterly unemployment, and we lag it by one quarter. For instance, the midpoint of the October 2016 to September 2017 estimate is 1 April 2017, the start of the second quarter of 2017. With the one-quarter lag, unemployment estimates from the second quarter of 2017 would serve as a control for road accident injuries in the third quarter of 2017 (i.e., July to September 2017). In other words, we use local authority unemployment estimates from the October 2016 to September 2017 data as the time-varying control for road accident injuries in the third quarter of 2017. 
Fuel price: To estimate fuel price at the local authority level, we proceed in three steps. First, we gathered monthly "Fuel Price Reports," published by the Automobile Association (AA) of the United Kingdom (Available at: https://www.theaa.com/driving-advice/driving-costs/fuel-prices). AA's fuel price reports provide estimates of price per litre for unleaded and diesel fuel, broken down by the 12 regions of England, Wales, Scotland, and Northern Ireland. These reports are available from 2016 to the present. Second, we backcasted the regional-level fuel price time series to 2009 by leveraging monthly information on fuel prices at the country-level, available from the Department for Business, Energy and Industrial Strategy since 2003

\section{(https://www.gov.uk/government/statistical-data-sets/oil-and-petroleum-products-weekly-}

$\underline{\text { statistics). }}$. To do so, we estimated the predicted values from an Ordinary Least Squares model where the regional fuel price is expressed as a function of region-, year- and month-fixed effects, and as a function of country-level monthly prices for fuel. As a third and final step, we obtained monthly price data at the local authority as the average of the prices for diesel and unleaded fuel prevailing in a given region, weighted by the number of diesel and non-diesel vehicles registered in each local authority within that region (data available from the Department for Transport and the Driver and Vehicle Licensing Agency for each local authority in each year:

https://www.gov.uk/government/statistical-data-sets/all-vehicles-veh01).

Introduction of CRASH and COPA: CRASH (Collision Recording and Sharing) and COPA (Case Overview and Preparation Application, adopted in London) are injury-based severity reporting systems where injuries are automatically converted to a pre-defined severity level. These systems differ substantially from the way British police forces traditionally recorded injuries from road traffic collisions. Individual police forces in Great Britain historically used their own independent data 
collection procedures for recording injuries arising from road traffic accidents, typically based on the judgment of the officer.

Supplementary Table A.2 below reports the adoption date for those police forces that introduced CRASH or COPA. We obtained the timeline of the introduction of these systems from the Department for Transport's 2017 annual report. ${ }^{12}$ The Department for Transport and the Home Office began rolling out CRASH starting in 2012 in Surrey. Further adoption beyond Surrey began in 2015, and by the end of 2016 nearly half of all English police forces had adopted the CRASH system. The Metropolitan Police Service in London adopted COPA during the latter part of 2016. Adoption dates in Supplementary Table A.2 should be considered as indicative, as there might have been phased introduction of the new systems.

\section{[Supplementary Table A.2 here]}

Initial estimates by the Department for Transport found that switching to the new systems added between $5 \%$ and $15 \%$ more Serious injuries to the UK-wide total. ${ }^{13}$ Further analysis by the Office for National Statistics adopted time-series and logistic regression models to compare the probability of observing a Serious over a Slight accident after the introduction of the CRASH/COPA systems, using accident data from 2005 to 2017. They find an estimated odds ratio for "Serious" accidents of 1.3 as a function of the new system, amounting to around 80,730 additional "Serious" injuries, which would have been recorded as "Slight" under the previous reporting system. ${ }^{14}$ Our findings confirm that the rollout of the CRASH and COPA systems is positively correlated with the number of Serious injuries recorded. In Table 2 of the main paper, we estimate that the introduction of the new reporting system is associated with a $31 \%$ increase in the number of Serious injuries. Since many police forces used both systems in the first few months of rollout, our estimates of the effect of CRASH/COPA on 
reporting of Serious injuries present a downward bias. CRASH/COPA is also associated with an increase in Slight and Total injuries - as the new system might have encouraged police officers to report more. These results suggest that the decoupling of Serious and Slight injuries, observed in Supplementary Figure A.1, was to some extent driven by the introduction of the new reporting systems. 


\section{Supplementary Table A.1. Uber rollout by date through 2017, Great Britain}

\begin{tabular}{|c|c|c|}
\hline Licensing Authority & Uber Rollout & Source \\
\hline London & June 28, 2012 & https://newsroom.uber.com/uk/4-years-of-moving-london/ \\
\hline Manchester & May 8, 2014 & $\begin{array}{l}\text { https://newsroom.uber.com/uk/uber-officially-launches-in- } \\
\text { manchester-with-free-uber-weekend/ }\end{array}$ \\
\hline $\begin{array}{l}\text { Stockport/Salford/Rochdale/Trafford/ } \\
\text { Wigan }\end{array}$ & May 8, 2014 & $\begin{array}{l}\text { https://www.manchestereveningnews.co.uk/news/greater- } \\
\text { manchester-news/uber-launch-bolton-bury-oldham-9165954 }\end{array}$ \\
\hline Leeds & November 14, 2014 & https://newsroom.uber.com/uk/uber-lands-in-leeds/ \\
\hline Birmingham & February 12, 2015 & https://newsroom.uber.com/uk/happy-birthday-birmingham/ \\
\hline Wakefield (suburb Leeds) & March 5, 2015 & https://newsroom.uber.com/uk/uber-lands-in-leeds-2/ \\
\hline Newcastle & April 17, 2015 & $\begin{array}{l}\text { https://newsroom.uber.com/uk/newcastle-your-uber-is-arriving- } \\
\text { now/ }\end{array}$ \\
\hline Bolton/Bury/Oldham & May 1, 2015 & https://newsroom.uber.com/uk/manchester-weve-just-gone-greater/ \\
\hline Bradford (suburb Leeds) & May 15, 2015 & $\begin{array}{l}\text { https://newsroom.uber.com/uk/bradford-your-uber-is-arriving- } \\
\text { now/ }\end{array}$ \\
\hline Huddersfield (Leeds) & May 22, 2015 & $\begin{array}{l}\text { https://newsroom.uber.com/uk/huddersfield-and-dewsbury-your- } \\
\text { uber-is-arriving-now/ }\end{array}$ \\
\hline Solihull (Birmingham) & May 27, 2015 & $\begin{array}{l}\text { https://newsroom.uber.com/us-alabama/birmingham-just-got- } \\
\text { bigger-welcome-to-the-family-solihull/ }\end{array}$ \\
\hline Bristol & June 5,2015 & https://newsroom.uber.com/uk/bristol-your-uber-is-arriving/ \\
\hline Sheffield & June 5,2015 & $\begin{array}{l}\text { https://newsroom.uber.com/uk/sheffield-your-uber-is-arriving-now- } \\
\text { 2/ }\end{array}$ \\
\hline Slough/Windsor/Maidenhead & June 5,2015 & https://newsroom.uber.com/uk/uber-goes-west/ \\
\hline Merseyside/Liverpool & August 12, 2015 & https://newsroom.uber.com/uk/merseyside-your-uber-is-arriving/ \\
\hline Glasgow & October 16, 2015 & https://newsroom.uber.com/uk/glasgow/ \\
\hline Luton & October 23, 2015 & https://newsroom.uber.com/uk/luton/ \\
\hline Rotherham (Sheffield) & October 30, 2015 & https://newsroom.uber.com/uk/rotherham-launch/ \\
\hline Edinburgh & November 6, 2015 & https://newsroom.uber.com/uk/edinburgh-launch/ \\
\hline Nottingham & November 6, 2015 & https://newsroom.uber.com/uk/nottingham-launch/ \\
\hline Portsmouth & November 13, 2015 & https://newsroom.uber.com/uk/portsmouth-launch/ \\
\hline Leicester & November 19, 2015 & https://newsroom.uber.com/uk/leicester-launch/ \\
\hline Tameside (Manchester) & November 20, 2015 & https://newsroom.uber.com/uk/tameside/ \\
\hline Southampton & April 8, 2016 & https://newsroom.uber.com/uk/southampton-launch/ \\
\hline Cardiff & April 22, 2016 & https://newsroom.uber.com/uk/cardiff-launch/ \\
\hline Sunderland (Newcastle) & April 22, 2016 & https://newsroom.uber.com/uk/sunderland/ \\
\hline Wolverhampton/Dudley/Walsall & May 20, 2016 & $\begin{array}{l}\text { https://www.expressandstar.com/news/local- } \\
\text { news/2016/05/20/uber-finally-arrives-in-wolverhampton-dudley- } \\
\text { and-walsall/ }\end{array}$ \\
\hline Bath & June 23, 2016 & $\begin{array}{l}\text { http://www.bathchronicle.co.uk/uber-launches-in-bath-everything- } \\
\text { you-need-to-know/story-29435381-detail/story.html }\end{array}$ \\
\hline Stoke-on-Trent & July 15, 2016 & https://twitter.com/BBCRadioStoke/status/757998522205663233 \\
\hline
\end{tabular}




\begin{tabular}{|l|l|l|}
\hline York & September 9,2016 & $\begin{array}{l}\text { http://www.yorkpress.co.uk/news/14732048.Uber_to_launch_in_Y } \\
\text { ork_today/ }\end{array}$ \\
\hline Newport & September 30, 2016 & $\begin{array}{l}\text { https://www.uber.com/en-GB/newsroom/were-on-the-road-in- } \\
\text { newport/ }\end{array}$ \\
\hline Brighton and Hove & $\begin{array}{l}\text { https://thetab.com/uk/sussex/2016/10/28/uber-arrived-brighton- } \\
13654\end{array}$ \\
\hline Cambridge/South Cambridgeshire & November 10, 2016 & https://www.uber.com/en-GB/blog/calling-cambridge-riders/ \\
\hline Chester & July 20, 2017 & https://www.uber.com/en-GB/blog/chester-weve-arrived/ \\
\hline
\end{tabular}




\section{Supplementary Table A.2. Adoption dates of new reporting systems}

\begin{tabular}{|l|l|l|}
\hline Police force & Reporting system & Adoption date \\
\hline Bedfordshire & CRASH & April 2016 \\
\hline Cambridgeshire & CRASH & May 2016 \\
\hline City of London & CRASH & November 2015 \\
\hline Cumbria & CRASH & January 2016 \\
\hline Devon and Cornwall & CRASH & December 2015 \\
\hline Durham & CRASH & March 2016 \\
\hline Essex & CRASH & November 2015 \\
\hline Gloucestershire & CRASH & November 2015 \\
\hline Hertfordshire & CRASH & April 2016 \\
\hline Humberside & CRASH & January 2016 \\
\hline Kent & CRASH & January 2016 \\
\hline London Metropolitan Police & COPA & November 2016 \\
\hline Norfolk & CRASH & February 2016 \\
\hline Northumbria & CRASH & April 2016 \\
\hline South Yorkshire & CRASH & January-February 2013; January 2016 \\
\hline Staffordshire & CRASH & May 2015 \\
\hline Suffolk & CRASH & February 2016 \\
\hline Surrey & CRASH & November 2012 \\
\hline Warwickshire & CRASH & November 2015 \\
\hline West Mercia & CRASH & December 2015 \\
\hline West Midlands & & \\
\hline & CRASH & November 2015 \\
\hline
\end{tabular}


Supplementary Figure A.1. Trends in road accident injuries by type (Index, 2009=100)

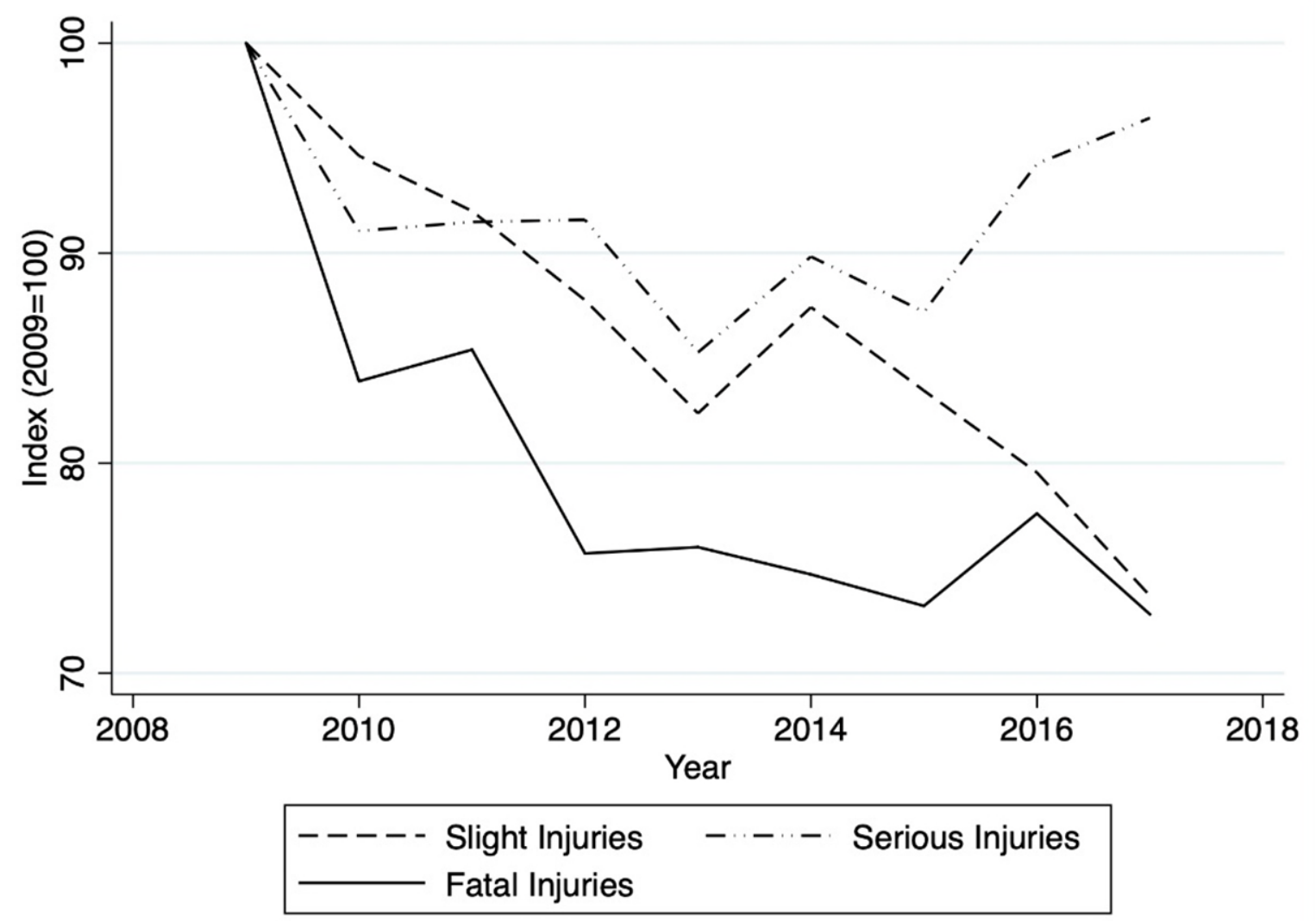

Supplementary Figure A.1 displays trends in road accident injuries from 2009 to 2017 (values are expressed in 2009 terms, where $2009=100$ and subsequent years are computed as the number of injuries in the year divided by the number of injuries in 2009 and then multiplied by 100). All categories of injuries were lower in 2017 compared to 2009. Fatal injuries decrease quasi-monotonically over time. Serious and Slight injuries follow a similar path up until 2015, when they start diverging, with Serious injuries nearly returning to 2009 levels. 
Supplementary Figure A.2. Uber availability over time

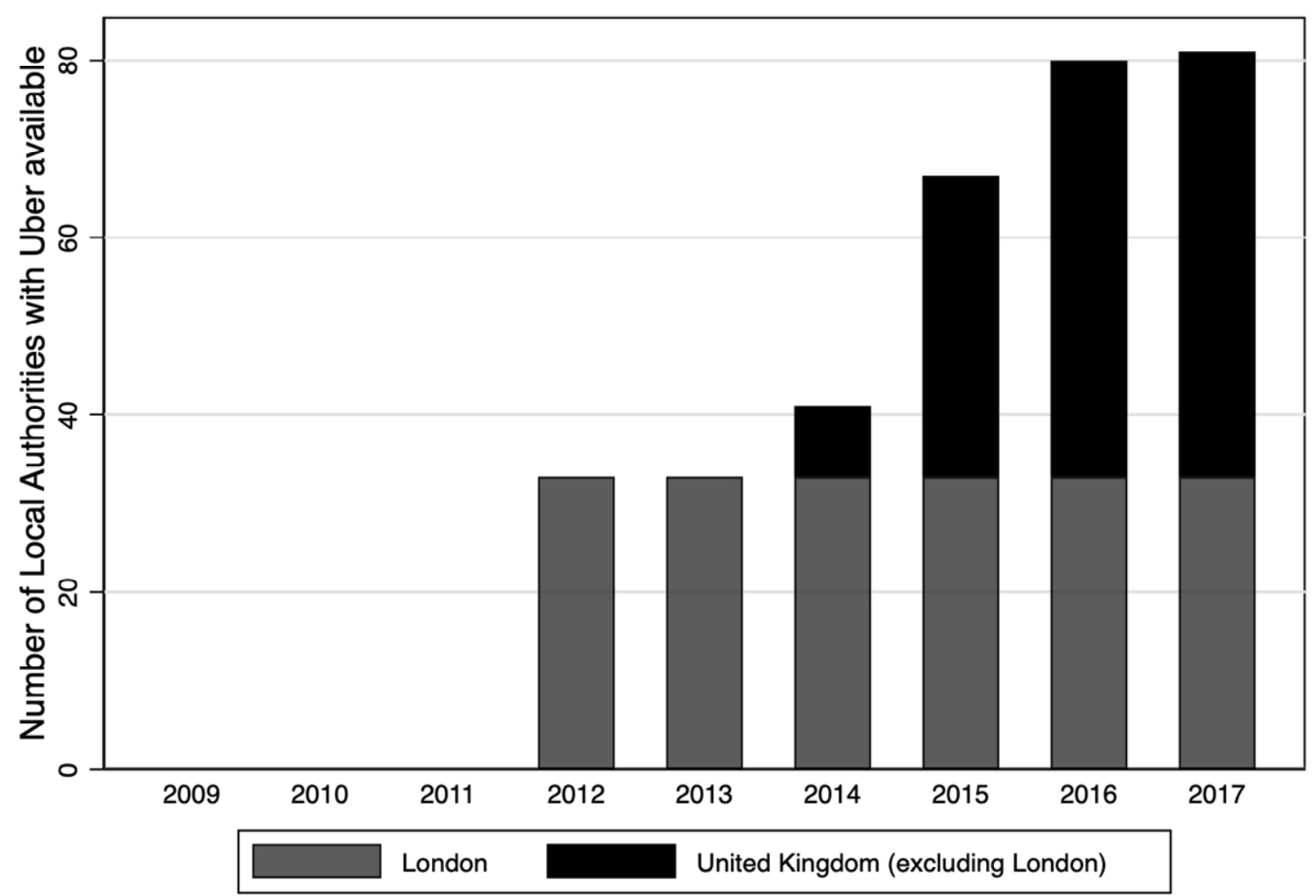

Northern Ireland is excluded from the analysis 


\section{Supplementary Appendix B. Robustness Checks}

In this appendix, we examine the extent to which our main results presented in Tables $2-5$ are robust to 1) our clustering of standard errors, 2) our operationalization of exposure to the risk of road accidents, and 3) our operationalization of the Uber deployment variable. Regarding clustering, in the main body of the paper we chose to cluster standard errors at the licensing-area $(N=347)$ rather than the local authority $(N=378)$ because it allowed us to relax the restrictive assumption of no correlation in the residuals across different local authorities within the Greater London metropolitan area. In Great Britain, Uber licenses are issued by local transport authorities, which administratively correspond to local council authorities, with the important exception of London. In London, Uber licenses are issued by Transport for London, which is responsible for the transport system over the 32 local authorities of the Greater London area. Hence, there are 31 fewer licensing-areas than local authorities since Uber licenses are issued for London as a whole rather than specific to boroughs.

In Supplementary Table B.1, we experiment with different levels of clustering of the standard errors, including at the local authority level (column 1). Consistent with results in Table 2, we find a statistically significant association between the rollout of Uber and Serious injuries. In Supplementary Table B.1 column (2), we cluster at the level of the 50 local police forces across England (38, excluding the City of London police), Scotland (8), and Wales (4). In fact, structural differences in local police force reporting standards, resources, and overall policing culture might introduce heteroscedasticity in the data. Clustering for police force areas is a conservative choice, as larger clusters result in wider standard errors. Nevertheless, in column (2) we still find a marginally significant negative association between Uber and Serious injuries. However, when clustering standard errors at the level of the 11 macro-regions in Great Britain, we do not observe a statistically significant association between Uber and any type of road accident injury (column 3). 
[Supplementary Table B.1 here]

In Supplementary Table B.2, we run a set of models using three different measures of exposure, to check whether our results are robust to alternative specifications of risk. We use local authority yearly VMT, the total number of vehicles registered in each year by local authorities (per 1,000 residents), and yearly population counts for each local authority. ${ }^{15,16}$ In Supplementary Table B.2 column (1), we show that switching to a yearly VMT exposure (versus monthly VMT in the main text) does not alter the significance of the Uber availability coefficients across the four dependent variables in our analysis. In column (2), when risk is captured as a function of the yearly number of vehicles (potentially) on the road within each local authority, we do not find substantial changes in the estimated effect of Uber on Serious injuries, which is negative and marginally significant. Finally, we also experiment using the total population in a local authority as our exposure measure. In column (3), we observe a negative correlation between the availability of Uber and the number of Serious injuries, significant at $\mathrm{p}<0.05$.

[Supplementary Table B.2 here]

Building on the analysis presented in Table 4 of the main paper, Supplementary Table B.3 tests two different operationalizations of a categorical variable measuring the deployment of Uber. In model 1, we replace the binary Uber indicator used in previous analyses with a variable categorizing observations into no Uber service present (1), Uber deployed for up to three months (2), and Uber deployed in a local authority more than three months (3) (i.e., a three month threshold). In model 2, we replace the binary Uber indicator used in other analyses with a variable categorizing observations into no Uber service present (1), Uber deployed for less than or equal to six months (2), and Uber deployed in a local authority more than six months (3) (i.e., a six month threshold). The purpose of using this categorical operationalization is to examine if the association between Uber and road 
accident injuries is lagged by some period of time. Inferences from Table B.3 are consistent with findings presented in Table 4 of the main text. We do not find evidence of an association between Uber and the number of Total, Slight, and Fatal injuries, whether in the period immediately after deployment of Uber or after several months. For Serious injuries, we actually observe a marginally significant positive association between Uber and road accident injuries during the first three months after the rollout of Uber, but then a significant decline in serious injuries in the period after three months. We similarly observe a decline in serious road accident injuries when switching to a six month threshold in the analysis presented on the right-side of the table. In sum, the decline in serious injuries after the deployment of Uber appears to be slightly delayed, likely because it takes a little time for Uber to recruit drivers and obtain customers after first being deployed in an area.

[Supplementary Table B.3 here] 


\section{Supplementary Table B.1 Alternative clustering of errors}

\begin{tabular}{rccr}
\hline & Local Authority & $\begin{array}{c}\text { Police-Force } \\
\text { Area } \\
(2)\end{array}$ & $\begin{array}{c}\text { Region } \\
(3)\end{array}$ \\
\hline Number of Injuries: & & & \\
Total & 0.01 & 0.01 & 0.01 \\
& $(0.02)$ & $(0.04)$ & $(0.04)$ \\
Slight & 0.03 & 0.03 & 0.03 \\
& $(0.01)$ & $(0.05)$ & $(0.06)$ \\
Serious & $-0.09 * * *$ & $-0.09+$ & -0.09 \\
& $(0.02)$ & $(0.05)$ & $(0.06)$ \\
Fatal & 0.02 & 0.02 & 0.02 \\
& $(0.06)$ & $(0.05)$ & $(0.05)$ \\
\hline Clusters & 40,824 & 40,824 & 40,824 \\
\hline
\end{tabular}

${ }^{+} \mathrm{p}<0.1,{ }^{*} \mathrm{p}<0.05,{ }^{* *} \mathrm{p}<0.01,{ }^{* * *} \mathrm{p}<0.001$.

Estimates from negative binomial models. Standard errors in parentheses. The twelve coefficients and standard errors represent results from twelve different regression models: four dependent variables (Total, Slight, Serious, and Fatal injuries) by three models with different cluster variables. For comparison, in Tables $2-5$ we clustered by licensing authority $(\mathrm{N}=347)$. All models include controls for the lagged unemployment rate, total population, the rate of taxis and PHVs, fuel price, and CRASH/COPA rollout. All models include local authority, month, and year fixed effects. 


\section{Supplementary Table B.2 Different exposure variables}

\begin{tabular}{cccc}
\hline & Yearly VMT & Vehicles Registered & Total Population \\
& $(1)$ & $(2)$ & $(3)$ \\
\hline Number of Injuries: & & & \\
Total & 0.01 & 0.02 & 0.01 \\
& $(0.03)$ & $(0.04)$ & $(0.04)$ \\
Slight & 0.03 & 0.03 & 0.03 \\
& $(0.04)$ & $(0.05)$ & $(0.05)$ \\
Serious & $-0.09+$ & $-0.09+12 *$ & $(0.06)$ \\
& $(0.05)$ & $(0.05)$ & -0.03 \\
Fatal & 0.02 & 0.03 & $(0.06)$ \\
\hline & $(0.06)$ & $(0.06)$ & 40,824 \\
\hline
\end{tabular}

${ }^{+} \mathrm{p}<0.1, * \mathrm{p}<0.05, * * \mathrm{p}<0.01, * * * \mathrm{p}<0.001$.

Estimates from negative binomial models. Standard errors in parentheses. The twelve coefficients and standard errors represent results from twelve different regression models: four dependent variables (Total, Slight, Serious, and Fatal injuries) by three models with different exposure variables. All models include controls for the lagged unemployment rate, total population, the rate of taxis and PHVs, fuel price, and CRASH/COPA rollout. All models include local authority, month, and year fixed effects. 


\section{Supplementary Table B.3 Different lags on Uber variable}

\begin{tabular}{|c|c|c|c|c|c|c|c|c|}
\hline & \multicolumn{4}{|c|}{ Three Month Threshold } & \multicolumn{4}{|c|}{ Six Month Threshold } \\
\hline & Total & Slight & Serious & Fatal & Total & Slight & Serious & Fatal \\
\hline Uber active $\leq$ & 0.01 & 0.01 & $0.05+$ & -0.09 & 0.00 & 0.01 & 0.02 & -0.03 \\
\hline Threshold & $(0.02)$ & $(0.02)$ & $(0.03)$ & $(0.09)$ & $(0.02)$ & $(0.02)$ & $(0.02)$ & $(0.09)$ \\
\hline Uber active > & 0.01 & 0.03 & $-0.11 *$ & 0.04 & 0.02 & 0.04 & $-0.12 *$ & 0.04 \\
\hline Threshold & $(0.04)$ & $(0.05)$ & $(0.05)$ & $(0.06)$ & $(0.04)$ & $(0.05)$ & $(0.06)$ & $(0.06)$ \\
\hline$N$ & 40,824 & 40,824 & 40,824 & 40,824 & 40,824 & 40,824 & 40,824 & 40,824 \\
\hline
\end{tabular}

Estimates from negative binomial models. Standard errors in parentheses. All models include controls for the lagged unemployment rate, total population, the rate of taxis and PHVs, fuel price, and CRASH/COPA rollout. All models include local authority, month, and year fixed effects. 


\section{Supplementary Appendix C. Replication with daily data}

To further investigate the robustness of our findings, we re-estimated all the models presented in Tables $2-5$ in the main body of the paper using daily instead of monthly data. This allows us to make full use of the available variation across local authorities before and after the introduction of Uber, and to increase substantially the degrees of freedom of our regression models. There were two leap years in the time series (2012 and 2016), and the total number of daily observations between 2009 and 2017 equals 1,242,486 (365 x $7+366 \times 2=3,287$ days; 378 local authorities x 3,287 days =1,242,486). For this analysis, we have included day-of-the-week dummy variables, in addition to local authority, month, and year fixed effects. Our inferences using the daily counts of injuries as our dependent variable are closely consistent with inferences based on the monthly counts as the dependent variable.

$$
\text { [Supplementary Tables C.1 - C.4 here] }
$$




\section{Supplementary Table C.1 Effect of Uber rollout on number of road accidents injuries, daily}

data

\begin{tabular}{|c|c|c|c|c|}
\hline & Total & Slight & Serious & Fatal \\
\hline \multirow[t]{2}{*}{ Intercept } & $-5.26 * * *$ & $-5.81 * * *$ & $-5.70 * * *$ & $-6.23 * * *$ \\
\hline & $(0.35)$ & $(0.40)$ & $(0.23)$ & $(0.55)$ \\
\hline \multirow[t]{2}{*}{ Uber Availability } & 0.02 & 0.03 & $-0.09+$ & 0.03 \\
\hline & $(0.04)$ & $(0.05)$ & $(0.05)$ & $(0.06)$ \\
\hline \multirow[t]{2}{*}{ Lagged Unemployment Rate } & 0.00 & 0.00 & $-0.01 *$ & 0.00 \\
\hline & $(0.00)$ & $(0.00)$ & $(0.01)$ & $(0.02)$ \\
\hline \multirow[t]{2}{*}{ Total Population (per 100K) } & $0.46 * *$ & $0.53 * *$ & 0.14 & -0.07 \\
\hline & $(0.15)$ & $(0.17)$ & $(0.10)$ & $(0.20)$ \\
\hline \multirow[t]{2}{*}{ Taxi \& PHVs (\%) } & $0.02 * * *$ & $0.03 * * *$ & $0.01 * * *$ & $0.01 * *$ \\
\hline & $(0.00)$ & $(0.00)$ & $(0.00)$ & $(0.00)$ \\
\hline \multirow[t]{2}{*}{ Fuel Price } & -0.03 & 0.02 & -0.11 & $-1.19 * * *$ \\
\hline & $(0.04)$ & $(0.04)$ & $(0.09)$ & $(0.35)$ \\
\hline \multirow[t]{2}{*}{ CRASH/COPA Rollout } & $0.07 * * *$ & $0.03 *$ & $0.31 * * *$ & 0.07 \\
\hline & $(0.01)$ & $(0.01)$ & $(0.03)$ & $(0.05)$ \\
\hline Local Authority FE & YES & YES & YES & YES \\
\hline Day of Week FE & YES & YES & YES & YES \\
\hline Monthly FE & YES & YES & YES & YES \\
\hline Year FE & YES & YES & YES & YES \\
\hline$N$ & $1,242,486$ & $1,242,486$ & $1,242,486$ & $1,242,486$ \\
\hline
\end{tabular}

${ }^{+} \mathrm{p}<0.1,{ }^{*} \mathrm{p}<0.05,{ }^{* *} \mathrm{p}<0.01,{ }^{* * *} \mathrm{p}<0.001$. Estimates from negative binomial models. Standard errors in parentheses. 


\section{Supplementary Table C.2. Robustness checks, daily data}

\begin{tabular}{rccc}
\hline & $\begin{array}{c}\text { Capped Injuries } \\
(1)\end{array}$ & Weekends & $\begin{array}{c}\text { Above 100k } \\
\text { Residents } \\
(3)\end{array}$ \\
\hline Number of Injuries: & & & \\
Total & 0.02 & 0.05 & 0.02 \\
& $(0.04)$ & $(0.03)$ & $(0.04)$ \\
Slight & 0.03 & 0.06 & 0.04 \\
& $(0.05)$ & $(0.04)$ & $(0.05)$ \\
Serious & $-0.09+$ & -0.07 & -0.08 \\
& $(0.05)$ & $(0.05)$ & $(0.04)$ \\
Fatal & 0.03 & 0.06 & 0.04 \\
& $(0.06)$ & $(0.09)$ & $(0.06)$ \\
\hline$N$ & $1,242,486$ & 532,980 & 861,194 \\
\hline
\end{tabular}

${ }^{+} \mathrm{p}<0.1,{ }^{*} \mathrm{p}<0.05,{ }^{* *} \mathrm{p}<0.01,{ }^{* * *} \mathrm{p}<0.001$.

Estimates from negative binomial models. Standard errors in parentheses. The twelve coefficients and standard errors represent results from twelve different regression models: four dependent variables (Total, Slight, Serious, and Fatal injuries) by three robustness tests. All models include controls for the lagged unemployment rate, total population, the rate of taxis and PHVs, fuel price, and CRASH/COPA rollout. All models include local authority, day of week, month, and year fixed effects. 


\section{Supplementary Table C.3. Association between Uber rollout and the number of road accident injuries, by the time since Uber's deployment, daily data}

\begin{tabular}{rcccc}
\hline & Total & Slight & Serious & Fatal \\
\hline $\begin{array}{r}\text { Uber active } \leq \\
1 \text { month }\end{array}$ & 0.00 & 0.00 & 0.01 & -0.31 \\
& $(0.02)$ & $(0.02)$ & $(0.04)$ & $(0.19)$ \\
Uber active $>$ & & & $-0.09+$ & 0.03 \\
1 month & $(0.02$ & 0.03 & $(0.05)$ & $(0.06)$ \\
\hline N & $1,242,486$ & $1,242,486$ & $1,242,486$ & $1,242,486$ \\
\hline+
\end{tabular}

${ }^{+} \mathrm{p}<0.1, * \mathrm{p}<0.05, * * \mathrm{p}<0.01, * * * \mathrm{p}<0.001$.

Estimates from negative binomial models. Standard errors in parentheses. All models include controls for the lagged unemployment rate, total population, the rate of taxis and PHVs, fuel price, and CRASH/COPA rollout. All models include local authority, day of week, month, and year fixed effects. The reference group in these models is a category indicating that Uber is not active in a given local authority at a given time point. 
Supplementary Table C.4. Heterogeneity of treatment for London vs. rest of Great Britain, daily data

\begin{tabular}{|c|c|c|c|c|}
\hline & Total & Slight & Serious & Fatal \\
\hline \multirow{3}{*}{$\begin{array}{r}\text { Uber } \\
\text { Availability }\end{array}$} & $-0.07 * *$ & $-0.07 * *$ & -0.01 & 0.09 \\
\hline & $(0.02)$ & $(0.03)$ & $(0.03)$ & $(0.07)$ \\
\hline & [0.94] & [0.93] & [0.99] & [1.09] \\
\hline \multirow[t]{3}{*}{ London } & 1.33 *** & $1.45^{* * *}$ & $0.65 * * *$ & 0.04 \\
\hline & $(0.04)$ & $(0.04)$ & $(0.07)$ & $(0.12)$ \\
\hline & {$[3.78]$} & [4.24] & [1.92] & [1.05] \\
\hline \multirow[t]{3}{*}{ Uber*London } & 0.19 *** & $0.24 * * *$ & $-0.21 * * *$ & $-0.16 *$ \\
\hline & $(0.02)$ & $(0.03)$ & $(0.03)$ & $(0.07)$ \\
\hline & [1.21] & {$[1.27]$} & {$[0.81]$} & {$[0.85]$} \\
\hline$N$ & $1,242,486$ & $1,242,486$ & $1,242,486$ & $1,242,486$ \\
\hline
\end{tabular}

${ }^{+} \mathrm{p}<0.1,{ }^{*} \mathrm{p}<0.05,{ }^{* *} \mathrm{p}<0.01, * * * \mathrm{p}<0.001$.

Estimates from negative binomial models. Standard errors in parentheses, and incidence rate ratios in brackets below the standard errors. All models include controls for the lagged unemployment rate, total population, the rate of taxis and PHVs, fuel price, and CRASH/COPA rollout. All models include local authority, day of week, month, and year fixed effects. 


\section{Supplementary Appendix D. Replication with the number of accidents as outcome variable}

In the main body of the paper, we focused on the effect of Uber availability on the number of recorded injuries. However, in this appendix we present results for a full set of models estimating the effect of Uber on a differently defined dependent variable, namely the total number of road accidents by local authority-month. Accidents and injuries are highly correlated (corr $=0.98)$, and therefore results presented in Supplementary Tables D.2 to D.5 below are highly consistent with results presented in Tables $2-5$. Supplementary Table D.1 presents a comparison of summary statistics for the two different dependent variables.

[Supplementary Table D.1 here]

In Supplementary Table D.2, we replicate the models reported in Table 2, finding mostly similar inferences. For Total, Slight, and Fatal accidents, we still do not observe a statistically significant association with the deployment of Uber. For Serious accidents, the coefficient remains negative, as it is in Table $2(-0.06$; CI: -0.15 to $0.03 ; \mathrm{p}=0.169)$. However, the association is no longer statistically significant.

[Supplementary Table D.2 here]

In Supplementary Table D.3, we present two different sensitivity checks in order to better characterise and test the robustness of the results presented in Supplementary Table D.2. In the parallel analysis of injuries we presented in Table 3, we started our assessment of robustness by examining whether our results were robust to a different handling of outlier accidents - i.e., accidents with very large numbers of injuries. Given that the analysis in Supplementary Table D.3 is focused on accidents rather than injuries, a similar analysis is not applicable. However, as in Table 3, in Supplementary Table D.3 we assess whether our findings are robust to whether we restrict the analysis to accidents occurring 
on the weekend, and also whether we restrict the analysis to large areas, specifically local authorities with more than 100,000 residents as of our first observation year (2009).

In the analysis of accidents on weekends in column (1), we see that the deployment of Uber yielded increases in both Total and Slight road traffic accidents. This finding diverges from our results that do not subset to weekends (Table D.2), and it also diverges from the similar analysis of injuries presented in Table 3 (column 2). However, in all cases we observe positive coefficients, and in Supplementary Table D.3 the coefficients for Total (0.07; CI: -0.005 to 0.13; $\mathrm{p}=0.035)$ and Slight (0.09; CI: 0.01 to $0.16 ; \mathrm{p}=0.023)$ accidents are statistically significant.

[Supplementary Table D.3 here]

In column (2) of Supplementary Table D.3, which subsets our data to only those local authorities with at least 100,000 residents as of 2009, our results almost exactly match our findings from Supplementary Table D.2.

As in Table 4 in the main paper, Supplementary Table D.4 replaces the binary Uber indicator used in other statistical models with a variable categorizing observations into (1) no Uber service present, (2) Uber deployed for less than or equal to one month, and (3) Uber deployed in a local authority more than one month. After Uber is initially introduced into an area, it may take some time before enough drivers are recruited and customers attracted to the service for Uber to have more than a minimal presence on the roads. Accordingly, in Table D.4 we test for a lagged association with this new categorical measure of Uber's presence in an area. Consistent with findings in Table 4, we do not find evidence of an association between Uber and the number of Total and Slight road accidents. In contrast to Table 4, for Serious accidents we do not find evidence of an association between Uber and 
road accidents, either in the first month after deployment or after one month. Another difference between Table D.4 and Table 4 can be seen in the relationship between Uber's deployment and fatal accidents. In Table 4 in the main text, we found a nonsignificant negative coefficient (-0.30; CI: -0.69 to $0.08 ; \mathrm{p}=0.118)$, but in Table D.4 we find a significant negative coefficient $(-0.38$; CI: -0.66 to $0.10 ; \mathrm{p}=0.007)$. Accordingly, in the first month after deployment, there is a significant decline in fatal accidents (Table D.4), but not necessarily a decline in the number of fatal injuries (Table 4).

[Supplementary Table D.4 here]

Turning to an examination of possible heterogeneous effects between London and the rest of Great Britain presented in Supplementary Table D.5, we find that the deployment of Uber is associated with a decline in Total and Slight road accidents outside of London. However, we do not find an association between Uber and Serious or Fatal accidents. These findings are consistent with results presented in Table 5, but contrast results in Supplementary Table D.2.

Turning to the interaction term in the table, the IRR technically represents the ratio of two IRRs: the effect of Uber on road accidents within London over the effect of Uber on accidents outside of London. Accordingly, the IRRs for our interaction term reveal that, for Total and Slight accidents, the effect of Uber is significantly stronger in London than outside. For Serious and Fatal injuries, we find the opposite. For Slight accidents, Uber is associated with an $18 \%$ increase in accidents in London boroughs $(1.24 \times 0.95=1.18)$. In contrast, for Serious injuries Uber is associated with a $17 \%$ decrease in accidents in London $(0.82 * 1.01=0.83)$.

[Supplementary Table D.5 here] 
Supplementary Table D.1 Summary statistics for accidents vs. injuries

\begin{tabular}{llcccc}
\hline & Mean & SD & Min & Max \\
\hline \multicolumn{2}{l}{ Dependent Variables } & & & & \\
Accidents: & Total & 31.9 & 25.2 & 0 & 343 \\
& Slight & 26.9 & 22.2 & 0 & 302 \\
& Serious & 4.6 & 4.0 & 0 & 53 \\
& Fatal & 0.4 & 0.7 & 0 & 7 \\
Injuries: & Total & 42.7 & 33.6 & 0 & 460 \\
& Slight & 35.5 & 29.3 & 0 & 404 \\
& Serious & 6.5 & 6.0 & 0 & 115 \\
& Fatal & 0.7 & 1.6 & 0 & 55 \\
\hline
\end{tabular}




\section{Supplementary Table D.2. Effect of Uber rollout on number of road accidents}

\begin{tabular}{|c|c|c|c|c|}
\hline & Total & Slight & Serious & Fatal \\
\hline \multirow[t]{2}{*}{ Intercept } & $-1.65 * * *$ & $-2.12 * * *$ & $-2.38 * * *$ & $-3.38 * * *$ \\
\hline & $(0.33)$ & $(0.37)$ & $(0.19)$ & $(0.35)$ \\
\hline \multirow[t]{2}{*}{ Uber Availability } & 0.04 & 0.05 & -0.06 & 0.02 \\
\hline & $(0.03)$ & $(0.04)$ & $(0.04)$ & $(0.05)$ \\
\hline \multirow[t]{2}{*}{ Lagged Unemployment Rate } & 0.00 & 0.00 & $-0.01 *$ & -0.01 \\
\hline & $(0.00)$ & $(0.00)$ & $(0.00)$ & $(0.01)$ \\
\hline \multirow[t]{2}{*}{ Total Population (per 100K) } & $0.41 * *$ & $0.48 * *$ & 0.11 & -0.19 \\
\hline & $(0.14)$ & $(0.15)$ & $(0.08)$ & $(0.13)$ \\
\hline \multirow[t]{2}{*}{ Taxi \& PHVs (\%) } & $0.02 * * *$ & $0.03 * * *$ & $0.01 * * *$ & 0.00 \\
\hline & $(0.00)$ & $(0.00)$ & $(0.00)$ & $(0.00)$ \\
\hline \multirow[t]{2}{*}{ Fuel Price } & -0.02 & 0.02 & $-0.15 *$ & $-1.03 * * *$ \\
\hline & $(0.04)$ & $(0.05)$ & $(0.07)$ & $(0.24)$ \\
\hline \multirow[t]{2}{*}{ CRASH/COPA Rollout } & $0.07 * * *$ & $0.03 * *$ & $0.31 * * *$ & $0.07+$ \\
\hline & $(0.01)$ & $(0.01)$ & $(0.03)$ & $(0.04)$ \\
\hline Local Authority FE & YES & YES & YES & YES \\
\hline Monthly FE & YES & YES & YES & YES \\
\hline Year FE & YES & YES & YES & YES \\
\hline$N$ & 40,824 & 40,824 & 40,824 & 40,824 \\
\hline
\end{tabular}




\section{Supplementary Table D.3. Robustness checks}

\begin{tabular}{rcc}
\hline & Weekends & $\begin{array}{c}\text { Above 100k } \\
\text { Residents } \\
(1)\end{array}$ \\
\hline Number of Injuries: & & \\
Total & $0.07 *$ & 0.04 \\
& $(0.03)$ & $(0.03)$ \\
Slight & $0.09 *$ & 0.05 \\
& $(0.04)$ & $(0.04)$ \\
Serious & -0.05 & -0.06 \\
& $(0.04)$ & $(0.04)$ \\
Fatal & 0.00 & 0.03 \\
& $(0.07)$ & $(0.05)$ \\
\hline$N$ & 40,824 & 28,296 \\
\hline
\end{tabular}

${ }^{+} \mathrm{p}<0.1,{ }^{*} \mathrm{p}<0.05,{ }^{* *} \mathrm{p}<0.01,{ }^{* * *} \mathrm{p}<0.001$.

Standard errors in parentheses. The eight coefficients and standard errors represent results from eight different regression models: four dependent variables (Total, Slight, Serious, and Fatal injuries) by two robustness tests. All models include controls for the lagged unemployment rate, total population, the rate of taxis and PHVs, fuel price, and CRASH/COPA rollout. All models include local authority, month, and year fixed effects. The model for Fatal accidents in column (2) was estimated using a Poisson regression model given lack of convergence in a negative binomial model. All other models were estimated with negative binomial regression. 


\section{Supplementary Table D.4. Association between Uber rollout and the number of road accident injuries, by the time since Uber's deployment}

\begin{tabular}{rcccc}
\hline & Total & Slight & Serious & Fatal \\
\hline Uber active $\leq$ & 0.01 & 0.01 & 0.04 & $-0.38 * * *$ \\
1 month & $(0.02)$ & $(0.21)$ & $(0.05)$ & $(0.14)$ \\
& & & & 0.03 \\
Uber active $>$ & 0.04 & 0.05 & -0.07 & $(0.05)$ \\
1 month & $(0.03)$ & $(0.04)$ & $(0.04)$ & 40,824 \\
\hline$N$ & 40,824 & 40,824 & 40,824 & \\
\hline
\end{tabular}

${ }^{+} \mathrm{p}<0.1, * \mathrm{p}<0.05, * * \mathrm{p}<0.01, * * * \mathrm{p}<0.001$.

Models for Fatal accidents were estimated using Poisson regression models given lack of convergence in negative binomial models. All other models were estimated with negative binomial regression. Standard errors are in parentheses. All models include controls for the lagged unemployment rate, total population, the rate of taxis and PHVs, fuel price, and CRASH/COPA rollout. All models include local authority, month, and year fixed effects. The reference group in these models is a category indicating that Uber is not active in a given local authority at a given time point. 


\section{Supplementary Table D.5. Heterogeneity of treatment for London vs. rest of Great Britain}

\begin{tabular}{rcccc}
\hline & Total & Slight & Serious & Fatal \\
\hline Uber & $-0.04+$ & $-0.05 * *$ & 0.01 & 0.05 \\
Availability & $(0.02)$ & $(0.03)$ & $(0.02)$ & $(0.06)$ \\
& {$[0.96]$} & {$[0.95]$} & {$[1.01]$} & {$[1.05]$} \\
& & & & \\
London & $1.38 * * *$ & $1.48 * * *$ & $0.69 * * *$ & $0.72 * * *$ \\
& $(0.03)$ & $(0.04)$ & $(0.07)$ & $(0.09)$ \\
& {$[3.96]$} & {$[4.40]$} & {$[1.99]$} & {$[2.06]$} \\
Uber*London & $0.17 * * *$ & $0.22 * * *$ & $-0.20 * * *$ & $-0.09+$ \\
& $(0.02)$ & $(0.03)$ & $(0.02)$ & $(0.06)$ \\
& {$[1.18]$} & {$[1.24]$} & {$[0.82]$} & {$[0.91]$} \\
\hline$N$ & 40,824 & 40,824 & 40,824 & 40,824 \\
\hline
\end{tabular}

${ }^{+} \mathrm{p}<0.1,{ }^{*} \mathrm{p}<0.05,{ }^{* *} \mathrm{p}<0.01,{ }^{* * *} \mathrm{p}<0.001$.

Models for Fatal accidents were estimated using Poisson regression models given lack of convergence in negative binomial models. All other models were estimated with negative binomial regression. Standard errors are in parentheses, and incidence rate ratios are in brackets below the standard errors. All models include controls for the lagged unemployment rate, total population, the rate of taxis and PHVs, fuel price, and CRASH/COPA rollout. All models include local authority, month, and year fixed effects. 


\section{Supplementary Information, References}

1. UK Office of National Statistics. Local authority district to country (December 2016) lookup in the United Kingdom. Available from: http://geoportal.statistics.gov.uk/datasets/localauthority-district-to-country-december-2016-lookup-in-the-united-kingdom.

2. Local Government Association. What is local government? [Internet]. 2019 [cited 2019 August 19]. Available from: https://www.local.gov.uk/about/what-local-government.

3. Politics.co.uk. Local government structure [Internet]. 2019 [cited 2019 August 27]. Available from: https://www.politics.co.uk/reference/local-government-structure.

4. UK Department for Transport. Road safety data. 8 November 2018. Available from: https://data.gov.uk/dataset/cb7ae6f0-4be6-4935-9277-47e5ce24a11f/road-safety-data (Accessed March 2, 2019).

5. UK Department for Transport. Instructions for the completion of road accident reports from non-CRASH sources. London, UK: Department for Transport; 2011. Available from: https://assets.publishing.service.gov.uk/government/uploads/system/uploads/attachment dat a/file/230596/stats20-2011.pdf.

6. UK Department for Transport. STATS19 road accident injury statistics - report form. London, UK: Department for Transport; 2018. Available from: https://assets.publishing.service.gov.uk/government/uploads/system/uploads/attachment dat a/file/230590/stats19.pdf.

7. Uber Technologies Inc. Uber newsroom [internet] 2019 [cited 2019 July 29]. Available from: https://www.uber.com/en-GB/newsroom/.

8. UK Department for Transport. Road traffic statistics, TRA8901: Motor vehicle traffic (vehicle miles) by local authority in Great Britain. 5 July 2018. Available from: 
https://assets.publishing.service.gov.uk/government/uploads/system/uploads/attachment dat a/file/801263/tra8901.ods (Accessed December 23, 2018).

9. UK Department for Transport. Road traffic statistics, TRA0305: Average daily traffic flow by month in Great Britain, 5-year average. 5 July 2018. Available from:

https://assets.publishing.service.gov.uk/government/uploads/system/uploads/attachment_dat a/ file/801203/tra0305.ods (Accessed February 5, 2019).

10. UK Department for Transport. Taxi and private hire vehicle statistics: 2018. 25 October 2018. Available from: https://www.gov.uk/government/statistics/taxi-and-private-hire-vehiclestatistics-england-2018 (Accessed July 26, 2018).

11. UK Office for National Statistics. MO1 Regional labour market: Modelled unemployment for local and unitary authorities. 22 January 2019. Available from: https://www.ons.gov.uk/employmentandlabourmarket/peoplenotinwork/unemployment/data sets/modelledunemploymentforlocalandunitaryauthoritiesm01/current (Accessed 21 February 2019).

12. UK Department for Transport. Reported road casualties in Great Britain: 2017 annual report. London, UK: Department for Transport; 2018. Available from: https://assets.publishing.service.gov.uk/government/uploads/system/uploads/attachment dat a/file/755698/rrcgb-2017.pdf.

13. UK Department for Transport. Reported road casualties Great Britain, annual report: 2016. London, UK: Department for Transport; 2017. Available from: https://www.gov.uk/government/statistics/reported-road-casualties-great-britain-annualreport-2016. 
14. UK Office for National Statistics. Estimating and adjusting for changes in the method of severity reporting for road accidents and casualty data: interim report. Newport, UK: Office of National Statistics; 2018.

15. UK Department for Transport. All vehicles (VEH01), VEH0105: Licensed vehicles by body type and local authority. 10 January 2019. Available from: https://assets.publishing.service.gov.uk/government/uploads/system/uploads/attachment dat a/file/794433/veh0105.ods. (Accessed February 24, 2019).

16. UK Office for National Statistics. National and local authority level population estimates. Available from:

https://www.ons.gov.uk/peoplepopulationandcommunity/populationandmigration/populatio nestimates/methodologies/nationalandlocalauthoritylevelpopulationestimates (Accessed November 12, 2018). 